Agricultura familiar e agroecologia: perfil da produção de base agroecológica do município de Pelotas/RS Roberto Antônio Finatto, Giancarla Salamoni

\title{
AGRICULTURA FAMILIAR E AGROECOLOGIA: PERFIL DA PRODUÇÃO DE BASE AGROECOLÓGICA DO MUNICÍPIO DE PELOTAS/RS
}

\author{
Family agriculture and agroecology: \\ profile of the agroecological production in the city of Pelotas/RS
}

Roberto Antônio Finatto

Mestrando em Geografia da Universidade Federal de Santa Catarina robertofinatto@gmail.com

Giancarla Salamoni Prof ${ }^{a}$ Doutora do Departamento de Geografia da Universidade Federal de Pelotas gi.salamoni@yahoo.com.br

Artigo recebido para publicação em 27/03/08 e aceito para publicação em 01/10/08

RESUMO: O segmento da agricultura familiar apresenta características específicas na sua organização, como a utilização de mão-de-obra familiar, menor dimensão territorial da unidade produtiva e a lógica ou racionalidade camponesa está voltada em atender as demandas da própria família e não, de imediato, as necessidades do mercado. Estes são alguns dos traços que permitiram sua reprodução ao longo do processo de desenvolvimento capitalista. Por outro lado, estas características representam a possibilidade de transição de um modelo de agricultura convencional, pautado no excessivo uso dos recursos naturais não-renováveis, para um sistema de produção agroecológico, que tem como base os pilares da sustentabilidade (ecológica, econômica, social, cultural, espacial/geográfica). A agroecologia pretende, assim, restabelecer as relações harmônicas entre o homem e seu espaço natural, minimizando o impacto das atividades agrícolas no ambiente e ampliando os benefícios da agricultura para além do espaço rural. Desta forma, este trabalho, pretende traçar um perfil da produção de base agroecológica no município de Pelotas/RS, fazendo uma caracterização geral da mesma, identificando sua situação e importância enquanto estratégia produtiva para os agricultores familiares do município.

Palavras-Chave: Agricultura familiar. Agroecologia. Desenvolvimento rural sustentável.

ABSTRACT: The segment of family agriculture presents specific characteristics in its organization, like the utilization of family labor, minor territorial dimension of the production unit and the logic or peasant rationalization is focused to attend the demands of the own family and not immediately the necessities of the market. These are some of the features which allowed their reproduction meanwhile the process of capitalist development. On the other hand, these characteristics represent the possibility of transition of one model of conventional agriculture, registered in the excessive use of the natural sources of sustainability (ecological, economical, social, cultural, space/geographic). The agroecology intends, this way, to reestablish the harmonious relations between men and its natural space, minimizing the impact of the agricultural activities in the environment and maximizing the agricultural benefits beyond the rural space. This way, this work, intends to set a profile of production of agroecological base in the city of Pelotas/RS, making a general characterization of it, identifying its situation and importance as a productive strategy to the family farmers of the city. 
Agricultura familiar e agroecologia: perfil da produção de base agroecológica do município de Pelotas/RS Roberto Antônio Finatto, Giancarla Salamoni

Key words: Family agriculture. Agroecology. Sustainable rural development.

\section{AGRICULTURA FAMILIAR: O MARCO TEÓRICO}

O segmento da agricultura familiar, internamente, apresenta-se bastante diversificado nas várias estruturas agrárias. Muitos estudos continuam a ser produzidos visando aprofundar o conhecimento acerca da produção familiar na agricultura, especulando sobre o seu destino, as formas de como este segmento irá se desenvolver no sistema capitalista de produção contemporâneo, seu processo de adaptação ao sistema de mercado, seu desenvolvimento paralelo ao sistema capitalista, ou ainda, a possibilidade de seu desaparecimento por completo com a intensificação das relações de produção capitalistas.

O que se deve levar em consideração, entretanto, é que este segmento se reproduz de maneiras tão diversas, que se faz necessário uma análise específica em cada espaço, situação e tempo, devido à diversidade de estratégias que o agricultor encontra para permanecer no campo. Além disso, o referencial teórico dos autores clássicos, que se dedicaram ao estudo da agricultura utilizado para a análise, deve ser considerado sempre inserido em seu contexto histórico, considerando a especificidade espaço-temporal em que as idéias e teorias foram desenvolvidas.

Nesse sentido, uma constatação merece destaque, é inegável que o segmento da agricultura familiar se desenvolve e persiste até hoje. Isso fica evidenciado na significativa quantidade de mão-deobra relativa à família empregada no campo e à diversidade (em quantidade e qualidade) de produtos oferecidos, por este segmento, para atender as demandas do mercado consumidor interno e mesmo o externo. Por isso, os agricultores familiares, são considerados essenciais para a produção de alimentos tanto da população rural quanto urbana.
Um dos principais teóricos que se dedicaram a analisar as relações capitalistas de produção foi o economista, filósofo e socialista alemão Karl Marx. Para Marx, os camponeses são considerados como uma classe específica no sistema social, pois reúnem as características das duas outras classes sociais. $\mathrm{Ou}$ seja, ao mesmo tempo em que são donos dos meios de produção também são trabalhadores. Nesse sentido, Marx considera o campesinato como uma classe em transição, seja rumando para a burguesia, tornando-se um empresário capitalista, seja para o proletariado, tornando-se um trabalhador assalariado livre. Assim, no desenvolvimento do capitalismo o campesinato seria extinto enquanto classe social (SILVA, 1986).

Ainda, o processo de modernização do campo levaria para este espaço as indústrias, promovendo o desaparecimento da pequena propriedade. A penetração das relações capitalistas tenderia a dissolver as relações não-capitalistas, o que exigiria uma reorganização das propriedades e o surgimento de novas relações de produção. Silva (1986), ao analisar o campesinato na obra Formações Econômicas Pré-Capitalistas de Marx, destaca que:

[...] se tomar-se ao pé da letra as palavras de Marx, nestes trechos, tem-se que a penetração do capital no campo implica, 'em primeira instância', a dissolução 'por toda a parte', não de algumas formas, mas 'das diversas formas' de produção não tipicamente capitalistas, inclusive 'tipos intermediários ou híbridos'. Portanto, não deve restar pedra sobre pedra: qualquer forma de produção que se assemelhe à camponesa deve inexoravelmente ser destruída pelo capital. (SILVA, 1986, p. 106).

Entretanto, não se pode analisar a teoria marxista para o campesinato de maneira ortodoxa, concluindo que o capitalismo ao penetrar no campo extinguiria por completo o modo de produção 
camponês familiar. Em algumas obras, Marx ao analisar as relações sociais, faz referência à possibilidade de, em determinados contextos, ser possível a sobrevivência e reprodução do segmento camponês. Dessa forma, ainda segundo Silva, Marx, "[...] apontava, sim, uma tendência, mas uma tendência geral e estrutural para o desenvolvimento do capitalismo no campo. Em 'escala social', o capital expropria os produtores familiares transformando-os, 'potencialmente', em trabalhadores assalariados." (SILVA, 1986, p.116).

Embora não seja possível encontrar um conceito específico para o campesinato nas obras de Marx, nas análises marxistas o campesinato é tratado como uma classe social específica denominada de classe para si, isto devido à falta de coesão, representação política e de organização entre seus componentes. Apesar de internamente no grupo familiar haver harmonia entre os componentes, externamente este segmento não possui capacidade de organização, fator este, que não os torna uma classe social em si, que seria uma classe organizada politicamente com objetivos definidos e atitudes engajadas na resolução de seus problemas estruturais coletivos.

Seguindo a linha do pensamento marxista, posteriormente, surgem Lênin e Kautsky, considerados neomarxistas, pois ampliaram a tese de Marx sobre o destino do campesinato no desenvolvimento do sistema capitalista de produção.

Lênin, revolucionário russo e líder do Partido Comunista, ao analisar a realidade Russa, propôs sua tese de que o camponês que, não possuiria um mínimo de terra e de condições de trabalho necessários à reprodução da família num contexto capitalista tenderia a desaparecer. Reconhece, também, que o agricultor familiar possui apenas dois caminhos a seguir, ou se torna parte de uma burguesia agrária com a obtenção de mais terras tornando-se apenas proprietário dos meios de produção, ou será expropriado, juntando-se a massa de trabalhadores assalariados.
Já o teórico político alemão Karl Kautsky estudou a superioridade das grandes explorações agrícolas frente às pequenas, enfocando o processo de aproximação da indústria na agricultura. Ao analisar o livro a Questão Agrária de Kautsky, Abramovay (1992) afirma que, "Kautsky procura provar teoricamente que ali onde os camponeses sobrevivem, isso não é sinônimo de eficiência, mas de superexploração, do fato de venderem seus produtos a preços que não cobrem sequer sua subsistência" (ABRAMOVAY, 1992, p. 46).

Kautsky realiza sua análise observando o camponês da Idade Média, onde a unidade familiar era praticamente autônoma, pois, além de cultivar os produtos, por meio da indústria doméstica transformava-os em bens que necessitava. Neste caso, o mercado servia apenas para atender ou suprir suas demandas secundárias não era exclusivamente dele que dependia a sobrevivência da propriedade. Essa capacidade de organização fortalecia a unidade familiar, considerada livre, uma vez que permitia a ela reproduzir-se impulsionada por seus recursos internos, não dependendo de subsídios oriundos externamente a unidade produtiva.

Entretanto, com o desenvolvimento do processo capitalista e o fortalecimento da indústria que, vai aos poucos penetrando no campo, surgem novas necessidades. O que anteriormente era produzido/transformando pelos camponeses na propriedade, passa a ser produzido pela indústria e, portanto, para adquirir estes produtos o camponês necessita de dinheiro, assim,

Quanto mais tal processo avança, e mais se desagrega a indústria doméstica a que se dedicava primitivamente o camponês, tanto mais aumenta a sua necessidade de dinheiro, não apenas para a compra de coisas dispensáveis, e mesmo supérfluas, mas também para a compra de coisas necessárias. Ele não pode mais lavrar sua terra, não pode mais prover a sua manutenção sem dinheiro. (KAUTSKY, 1980, p. 3).

Neste sentido, ocorre um movimento 
contraditório, ao mesmo tempo em que a indústria se une à agricultura, acaba se distanciando dela (a indústria doméstica). Aquela indústria doméstica primitiva, onde o camponês era livre para produzir o que necessitava deixa de existir. Surge, assim, um novo padrão de indústria que integra o agricultor a um único processo produtivo, de caráter urbanoindustrial, tornando-o dependente, pois necessita dos produtos industrializados, justamente pelo fato de ter deixado de produzí-los.

Dessa forma, a aproximação da indústria com a agricultura cria duas situações novas, aquela anteriormente citada, onde o agricultor torna-se dependente, e uma outra que aproxima as grandes propriedades da indústria, enquanto que as pequenas seriam cada vez mais marginalizadas, pois a infraestrutura exigida pela indústria, para ser usada nas práticas agrícolas, demanda elevados investimentos monetários e o pequeno proprietário, via de regra, não tem condições de adequar-se ao novo padrão produtivo.

Outro autor que se dedicou aos estudos da dinâmica funcional da agricultura familiar foi Alexander Chayanov (1974), centrando sua análise na estrutura interna da organização familiar, considera que este segmento é desprovido de uma lógica capitalista, a qual tem na produção a oportunidade de retirar mais-valia, por meio da exploração de mãode-obra e pelos abusivos preços dos produtos comercializados. A lógica camponesa, por outro lado, é mediada por relações não-capitalistas ou minimamente capitalistas, essa característica primordial torna-se fundamental para se estudar este segmento, balizados por essas relações é que os camponeses desenvolvem suas atividades, trabalham a terra e a consideram como patrimônio familiar.

Para Chayanov, a produção familiar não se apresenta como uma forma residual, que não possui capacidade de evolução, mas se adapta, no interior do sistema capitalista de produção de acordo com suas possibilidades, e por estar condicionada a este sistema econômico, muitas vezes, é auto-explorada, sendo esta, a única solução para suprir suas necessidades.
Assim, o agricultor se sujeita às demandas do mercado, não se impõe, repensando suas estratégias se o mercado exigir uma nova postura de trabalho (WANDERLEY, 1989).

É importante analisar que a auto-exploração é uma característica presente nas unidades de produção familiar. Quando o produtor necessita aumentar sua renda para pagar um financiamento ou adquirir alguma mercadoria que melhore o conforto da família, por exemplo, ao contrário da empresa capitalista que aumenta o valor do produto para o mercado; o agricultor familiar aumenta a quantidade da sua produção, assim intensifica a força de trabalho, se necessário dobra sua jornada para a obtenção do dinheiro necessário.

Outra contribuição importante de Chayanov foi a criação da teoria da "diferenciação demográfica". A família, neste caso, é orientada em suas estratégias, pelo número de pessoas que contribuem para as atividades necessárias à manutenção da unidade familiar, a quantidade de força de trabalho disponível regula a quantidade de terra a ser adquirida e cultivada, bem como, as aspirações que o agricultor projeta pra o seu futuro. $\mathrm{O}$ equilíbrio entre braços e bocas é uma busca constante na agricultura familiar. Chayanov analisa esta questão na Rússia, quando as famílias escolhiam o tamanho da propriedade a ser explorada de acordo com a mão-de-obra disponível para o desenvolvimento das atividades agrícolas.

Entretanto, em meio aos questionamentos, investigações e suposições acerca do destino das explorações familiares, tem-se como primeiro desafio sua própria conceituação. Estabelecer critérios que permitam mensurar a lógica familiar de determinada exploração agrícola é bastante complexo. Para Lamarche,

A exploração familiar, tal como a concebemos, corresponde a uma unidade de produção agrícola onde propriedade e trabalho estão intimamente ligados à família. A interdependência desses três fatores no funcionamento da exploração engendra necessariamente noções mais abstratas e 
complexas, tais como a transmissão do patrimônio e a reprodução da exploração. (LAMARCHE, 1993, p. 15).

O segmento familiar apresenta-se como singular e, portanto, remete a uma complexidade também peculiar, para ser possível caracterizar determinada exploração como familiar ou não familiar faz-se necessário que se tome como referência vários critérios, que abranjam a amplitude das formas que este segmento encontrou e encontra para se reproduzir em meio as relações capitalistas de produção.

Segundo Lamarche, as estratégias de produção e reprodução da exploração familiar são organizadas e pensadas mediante dois domínios, seu passado histórico, ou o "modelo original”, onde estão presentes suas raízes culturais e um modo de vida mais tradicional e no outro extremo o que projetam para o seu futuro, o que e como pretendem desenvolver internamente na própria unidade produtiva. Entretanto, o que balizará e determinará seu ritmo de desenvolvimento para o que Lamarche denomina de "modelo ideal", depende, também, da sociedade, do que ela elaborou para o segmento familiar, principalmente, no que se refere ao desenvolvimento de políticas públicas, como acesso ao crédito, é disso que resulta o estado em que este segmento se encontra, seja de desenvolvimento, exploração ou até mesmo extinção (LAMARCHE, 1993).

Um aspecto importante e que tem contribuído para uma reorganização das unidades produtivas familiares é o processo de modernização da agricultura que altera a face da organização familiar tradicional, um desses traços que marcam esta transformação é que, com o passar do tempo, a estrutura familiar é marcada pela diminuição no número de filhos, isso deve ser pensado de maneira integrada ao modelo vigente que cria novas necessidades onde a estrutura familiar anteriormente consolidada já não tem como suportar.

Nas palavras de Wanderley, "esta agricultura moderna tem, a este respeito, uma dupla característica: sua integração, sob formas diversas aos mecanismos de mercado e aos processos de reprodução do capital e a 'abertura' do mundo rural ao modo de vida moderno" (WANDERLEY, 1989, p. 25)

Outro traço presente na organização familiar de produção é a mão-de-obra empregada nas atividades agrícolas, em determinados períodos do ano quando a quantidade de trabalho se intensifica em especial nas épocas do plantio e na colheita da produção, tem-se a necessidade de aumentar a mãode-obra disponível o que faz com que o agricultor recorra ao auxílio de membros de outras unidades produtivas, geralmente próximas a sua.

Assim, as relações de parentesco ou mesmo os laços afetivos de vizinhança acentuam-se e os produtores prestam auxílios uns para com os outros. Essa relação é desprovida de qualquer lógica capitalista, ou seja, como retribuição pela ajuda prestada o produtor que recebeu o auxílio em outra oportunidade retribui com sua própria força de trabalho (ou de algum outro componente da família) o auxílio recebido. Esse tipo de troca de serviço é conhecido como ajuda mútua.

De maneira mais isolada e menos freqüente, o produtor familiar recorre à contratação de mão-deobra para atender as demandas de trabalho da unidade, tal situação acontece, geralmente, quando os filhos estão pequenos e ainda não representam força de trabalho agrícola ou ainda quando algum dos membros da família está impossibilitado de se dedicar às atividades produtivas. Este sistema de ajuda é desprovido de qualquer contrato formal, e resume-se a execução de trabalhos pontuais, ou que exigem poucos dias ou semanas para serem executados.

A relação com a propriedade é outro traço marcante no segmento da agricultura familiar, a noção de propriedade, o apego a terra está muito presente. Geralmente, é nessa mesma unidade produtiva que os antepassados do atual produtor viveram e constituíram suas famílias, ainda a possibilidade de trabalhar a terra, cultivar os produtos que preferir conferem ao camponês uma sensação de autonomia e uma relação intrínseca com sua unidade produtiva. 
Dessa forma, torna-se inegável que o segmento familiar é movido por uma racionalidade camponesa específica e que se organiza e reorganiza com o intuito de permanência no atual sistema econômico. Estas características intrínsecas ao segmento de produção agrícola familiar permitem aproximá-la aos princípios/estratégias dos ideais da sustentabilidade, favorecendo o surgimento de uma nova perspectiva no espaço rural, na busca por novas relações entre o homem e o ambiente, configurando novas dinâmicas nos âmbitos sociais, econômicos e culturais no espaço agrário.

\section{DESENVOLVIMENTO SUSTENTÁVEL E A SUA RELAÇÃO COM A AGRICULTURA FAMILIAR}

$\mathrm{Na}$ medida em que, aparentemente, ocorre uma homogeneização espacial, comandada pelo capital internacional, que se polariza pelos diferentes países, sobressaem os custos ambientais, e, principalmente, sociais. Entretanto, este padrão produtivo capitalista que busca se expandir tanto sobre o espaço urbano quanto rural, objetivando atingir taxas máximas de lucro, age de forma desigual nos lugares, pois estes apresentam níveis diferenciados quanto à capacidade de absorção tecnológica, condicionados por suas características intrínsecas e historicamente consolidadas. Esta relação dialética resulta numa disparidade acerca das possibilidades de desenvolvimento local, que cria desigualdades entre as diferentes regiões geográficas.

Assim, tem-se o uso indiscriminado dos recursos naturais tanto dos renováveis quanto dos nãorenováveis para dar suporte às ações da supraestrutura política e da estrutura econômica na tentativa de promover uma maximização dos lucros. A lógica do capital nacional e/ou internacional é, desta forma, sobreposta aos interesses locais.

Nesse sentido, dadas as alterações espaciais ocorridas, o espaço pode ser considerado como "um sistema de objetos cada vez mais artificiais, povoado por sistemas de ações igualmente imbuídos de artificialidade, e cada vez mais tendente a fins estranhos ao lugar e a seus habitantes" (SANTOS, 1997, p. 51).

Essa artificialização do meio natural, não poderia deixar de causar significativas alterações na dinâmica dos ecossistemas. Ao mesmo tempo em que o desenvolvimento da técnica criou comodidades e proporcionou o desenvolvimento de um modo de vida moderno (aos que, dispondo de recursos financeiros, conseguiram ter acesso a ele), em alguns locais acarretou impactos negativos significativos ao meio natural, priorizando um padrão de vida incompatível com a capacidade de regeneração da natureza.

Diante desta problemática, principalmente no que concerne ao uso e dilapidação dos recursos naturais, surgem propostas alternativas de desenvolvimento que privilegiam as várias dimensões do espaço geográfico (ambiente, sociedade, cultura, política, economia, etc.). É importante destacar que, embora os problemas econômicos e sociais já fossem bastante representativos e graves ao longo do século XX, é com a temática ambiental, levantada pelos movimentos ambientalistas, que se buscam novas estratégias de desenvolvimento e não mais um "modelo" que seja sinônimo apenas de crescimento econômico.

Nesse sentido, vive-se, atualmente, como defendem alguns autores, um momento de transição de paradigmas que, de acordo com Becker "é uma transição que se revela nas múltiplas dimensões de uma crise decorrente do esgotamento do paradigma dominante e se pré-anuncia na emergência de um novo paradigma" (BECKER, 2002, p. 31).

Este paradigma emergente, inicialmente, convencionou-se denominar de eco desenvolvimento, tendo como foco a implantação de um relacionamento mais harmonioso do homem com o meio natural. Posteriormente, o termo foi substituído por desenvolvimento sustentável, distinguindo-se do anterior pelo seu caráter auto-sustentável (MONTIBELLER, 2004).

Surge, assim, o termo desenvolvimento 
sustentável amparado na idéia de repensar as formas de apropriação do meio natural pelo homem, elaborando novas estratégias produtivas na tentativa de minimizar os custos socioambientais ocasionados pelo atual modelo produtivo. De diferentes formas e defendidas por distintos atores sociais, como organizações-não-governamentais, cientistas, poder público e sociedade em geral, emerge a preocupação acerca das necessidades de revisão dos efeitos devastadores ocasionados pela exploração dos recursos naturais pelo homem. Cabe destacar o papel desempenhado pelos movimentos ambientalistas, organizados com mais intensidade por volta da metade do século XX, na busca pela preservação ambiental e que se revestem de importância significativa para contestar o modelo de desenvolvimento proposto para as sociedades contemporâneas.

Segundo Montibeller (2004), no Brasil, a presença do ambientalismo deve ser situada nos anos 1970, quando sociedade e estado passam a manter relações complementares e contraditórias, a sociedade civil tende a pressionar o estado a adequar a legislação em favor das causas ambientais. Ainda, segundo o mesmo autor, "na década seguinte a disseminação da preocupação social com a deteriorização ambiental transforma o ambientalismo brasileiro em um movimento multissetorial e complexo" (MONTIBELLER, 2004, p. 39).

A partir da década de 1970 definem-se, também, em nível mundial, ações que promovem o debate em torno do desenvolvimento sustentável. Entre as principais destacam-se a Conferência de Estocolmo em 1972, que chamou a atenção para a gravidade do desgaste ambiental frente a sua exploração indiscriminada, a Conferência Mundial sobre Conservação e Desenvolvimento, em 1986, realizada na cidade de Ottawa no Canadá e, mais recentemente, em 1992, na cidade do Rio de Janeiro, no Brasil, realizou-se a Eco-92, tendo como principal resultado a construção de um conjunto de estratégias de desenvolvimento que prezem por um novo padrão de desenvolvimento, que seja o sustentável, sendo denominada de Agenda 21. Sobre este último evento Candiotto e Corrêa (2004) esclarecem:
O principal aspecto da Rio-92 foi a constituição de um espaço público global com relativa capacidade para construir consensos sobre a questão ambiental, além da formulação da Agenda 21 global, que indicaria as diretrizes para o desenvolvimento sustentável no planeta. (CANDIOTTO ; CORREAA, 2004, p. 268).

A sustentabilidade é percebida como um instrumento de transformação com diferentes escalas temporais entre os autores. Para muitos, a sustentabilidade é considerada como um caminho, um meio de se atingir outras formas de desenvolvimento, enquanto que para outros ela é considerada como um resultado, já formatado, de uma nova abordagem de desenvolvimento. De acordo com Becker,

sustentabilidade deve ser compreendida como as múltiplas alternativas que cada localidade, região ou nação têm, pelas suas diferenças culturais, ambientais e valores (éticos e morais) de se inserir no processo geral de desenvolvimento. Em outras palavras, sustentabilidade deve ser entendida como a capacidade de uma região em constituir seu padrão de desenvolvimento, num padrão de desenvolvimento diferenciado. (BECKER, 2002, p. 77).

Esta visão pretende considerar a sustentabilidade como um meio para se atingir uma situação de desenvolvimento pautado nas potencialidades locais, pensando-se assim em um sistema de desenvolvimento local e regional.

A idéia central em que está amparado o ideal da sustentabilidade remete, de imediato, a uma visão sistêmica onde possam ser contemplados todos os aspectos que conduzem ao desenvolvimento, as estratégias devem ser orientadas no sentido de reaproveitar os fluxos de matéria e energia tanto naturais quanto às artificialmente criadas. O termo desenvolvimento reveste-se assim de um significado qualitativo com a finalidade de atingir uma vida digna a todos, pautado nas necessidades locais de cada população com critérios preservacionistas quanto ao uso dos recursos naturais disponíveis (SALAMONI, 2000). 
Um viés importante nas ações do desenvolvimento sustentável refere-se também à valorização das potencialidades locais, sejam elas relacionadas ao meio físico, daí propor o aproveitamento dos recursos paisagísticos (turismo rural, por exemplo) ou, ao patrimônio cultural, por meio da valorização de uma herança cultural típica de determinado lugar ou região.

Os agroecossistemas familiares também representam traços compatíveis com os princípios do desenvolvimento sustentável. A identificação e a sistematização destas características permitem o redesenho dos agroecossistemas, adaptando-os aos princípios de uma nova proposta de desenvolvimento, que priorize os pilares da sustentabilidade.

\section{AAGRICULTURA FAMILIAR NO CONTEXTO DO DESENVOLVIMENTO RURAL SUSTENTÁVEL}

Diante das buscas por novos sistemas produtivos e organizacionais que primem por estratégias produtivas sustentáveis, o segmento da agricultura familiar apresenta características compatíveis com o ideário da sustentabilidade.

Ao trabalhar movida por uma lógica específica, a agricultura familiar possui valores construídos na unidade produtiva, decorrentes de uma simbiose entre o ecossistema e o agricultor que trabalha diretamente na terra. Desta forma, as tradições culturais são fortemente influenciadas pelo meio, onde há uma significativa interação, representando um traço a ser mantido pelos sucessores do grupo familiar que, amparados por técnicas tradicionais, se relacionam mais harmoniosamente com o ambiente natural em que desenvolvem suas atividades, tanto as relacionadas às atividades técnicas na agricultura quanto às sociais.

Estas características ganham maior importância quando comparadas às explorações patronais que, devido às suas práticas agrícolas e a lógica empresarial adotada nas atividades, tendem a ocasionar significativos prejuízos ambientais (contaminação de mananciais hídricos pelo elevado uso de agrotóxicos, esgotamento do solo, lixiviação, etc.) e sociais (baixo emprego de mão-de-obra ocasionando o êxodo rural, entre outras conseqüências). De acordo com Franklin,

Uma das principais diferenças entre o produtor familiar e o empresário capitalista é que o primeiro precisa produzir, de certa forma, independentemente do mercado, pois ele e sua família vivem dos produtos da terra, enquanto que o segundo pode decidir mais livremente onde e como investir seu capital. Ao mesmo tempo, enquanto que o empresário capitalista pode despedir empregados considerados 'excedentes', numa lógica de racionalização econômica, o produtor familiar não pode fazer o mesmo com seus trabalhadores, membros de sua família: seu comprometimento de trabalho pode ser considerado como total; seu objetivo é maximizar a utilização de trabalho em lugar de maximizar o lucro ou algum outro indicador de eficiência (apud BRUMER, 1994, p. 90).

$\mathrm{O}$ agricultor familiar torna-se, neste contexto, importante foco de transformação na medida em que pode alterar seus sistemas produtivos, seus cultivos, a utilização de insumos, de acordo com suas necessidades sem precisar contratar mão-de-obra extra. O grupo familiar é que orienta as mudanças no sistema produtivo.

A relação do agricultor familiar com sua terra não se pauta apenas na produção para a comercialização da produção, mas ele se identifica com o lugar que trabalha e vive. Em muitos casos, foi no mesmo "pedaço" de terra que seus antepassados viveram, o que torna o lugar carregado de um sentimento de posse e identificação (valores simbólicos). Nestes sistemas de organização familiar, "a ecologia não representa somente a base de sua estrutura de produção, mas uma dimensão abrangente, relacionada à totalidade da vida do agricultor e fundamento de reprodução social da família" (CANUTO; SILVEIRA; MARQUES, 1994, p.61).

Ainda de acordo com Canuto, Silveira e 
Marques (1994) os agricultores familiares, a quem denominam de oikológicos, representam grande potencial para outro sistema de desenvolvimento,

Em relação à sua importância enquanto grupo econômico, os oikológicos são sistemas minoritários e cada vez mais escassos. No entanto, representam as últimas fontes preservadas de biodiversidade e do conhecimento necessário para gerir tal diversidade em sistemas agrícolas complexos. Desse modo, são sistemas com potencial para fornecer informação genética e tecnológica para incrementar a sustentabilidade de outros sistemas. (CANUTO; SILVEIRA; MARQUES, 1994, p. 61 e 62).

Neste sentido, o espaço rural reveste-se de especial interesse na medida em que fornece possibilidades para propiciar um desenvolvimento sustentável que priorize os aspectos sociais, como a qualidade de vida das populações. Tal situação deve ser visionada por políticas públicas adequadas que fomentem a substituição de técnicas, a valorização das tradições locais, para a partir daí ser possível a construção de estratégias pautadas em potencialidade locais e regionais, promovendo o desenvolvimento do grupo local que encontra-se diretamente vinculado a atividade desenvolvida.

Quanto ao impacto da agricultura no ambiente, intensificaram-se há alguns anos o debate sobre técnicas de agricultura orgânica, com a substituição de insumos convencionais por alternativos, que representa um importante recurso para minimizar o impacto no espaço natural, entretanto, para uma sistematização mais eficiente do processo produtivo, a fim de concretizar um projeto agroecológico, tornando-o sustentável, é necessário pensar a agricultura nas suas multifacetadas dimensões, e é o segmento de produção familiar que apresenta características nada desprezíveis para esta transformação.

\section{CARACTERIZAÇÃO DO MUNICÍPIO DE PELOTAS/RS}

O município de Pelotas, considerando-se as coordenadas geográficas, situa-se entre os paralelos de 31 e 32 graus de latitude sul, estendendo-se de $31^{\circ} 20^{\prime}$ a $31^{\circ} 48^{\prime}$, caracterizado assim por uma latitude média, inserido na zona temperada do sul (ROSA, 1985) - conforme mapa 1. Ainda, de acordo com o Instituto Brasileiro de Geografia e Estatística - IBGE, o município possui população de 339.934 habitantes.

O município de Pelotas apresenta características geográficas bastante peculiares, inserido na Encosta do Sudeste, uma das regiões fisiográficas do Rio Grande do Sul, seu território "se estende das mais baixas ondulações da encosta oriental da Serra dos Tapes até a planície sedimentar da margem ocidental do Canal São Gonçalo" (ROSA, 1985, p. 11).

Neste sentido, este município é caracterizado por apresentar distintas configurações espaciais na sua estrutura agrária. Apresenta pequenas unidades agrícolas, ou seja, de menor dimensão territorial, marcadas pela forte presença da agricultura familiar com o desenvolvimento da policultura, nas áreas com maiores declividades e não apropriadas para a mecanização. Neste espaço, também, predomina a colonização alemã, italiana, pomerana, francesa, entre outras.

Por outro lado, na área localizada na planície sedimentar há uma forte presença de lavouras empresariais, onde as grandes lavouras patronais são as principais representantes, configurando um espaço geometricamente organizado, sendo que a orizicultura predomina como principal atividade produtiva e a formação étnica apresenta-se mais variada.

O segmento que merece destaque, neste caso, é o da agricultura familiar caracterizado pelo sistema agrícola de policultura, com a produção de frutas, como o pêssego, hortigranjeiros, e o fumo, entre outros produtos. É no segmento da agricultura familiar, que se apresenta bastante representativo no 
Agricultura familiar e agroecologia: perfil da produção de base agroecológica do município de Pelotas/RS Roberto Antônio Finatto, Giancarla Salamoni

município, que a produção de base agroecológica encontra suas possibilidades de expansão facilitadas pelos elementos internos e externos da produção que caracterizam a agricultura familiar.

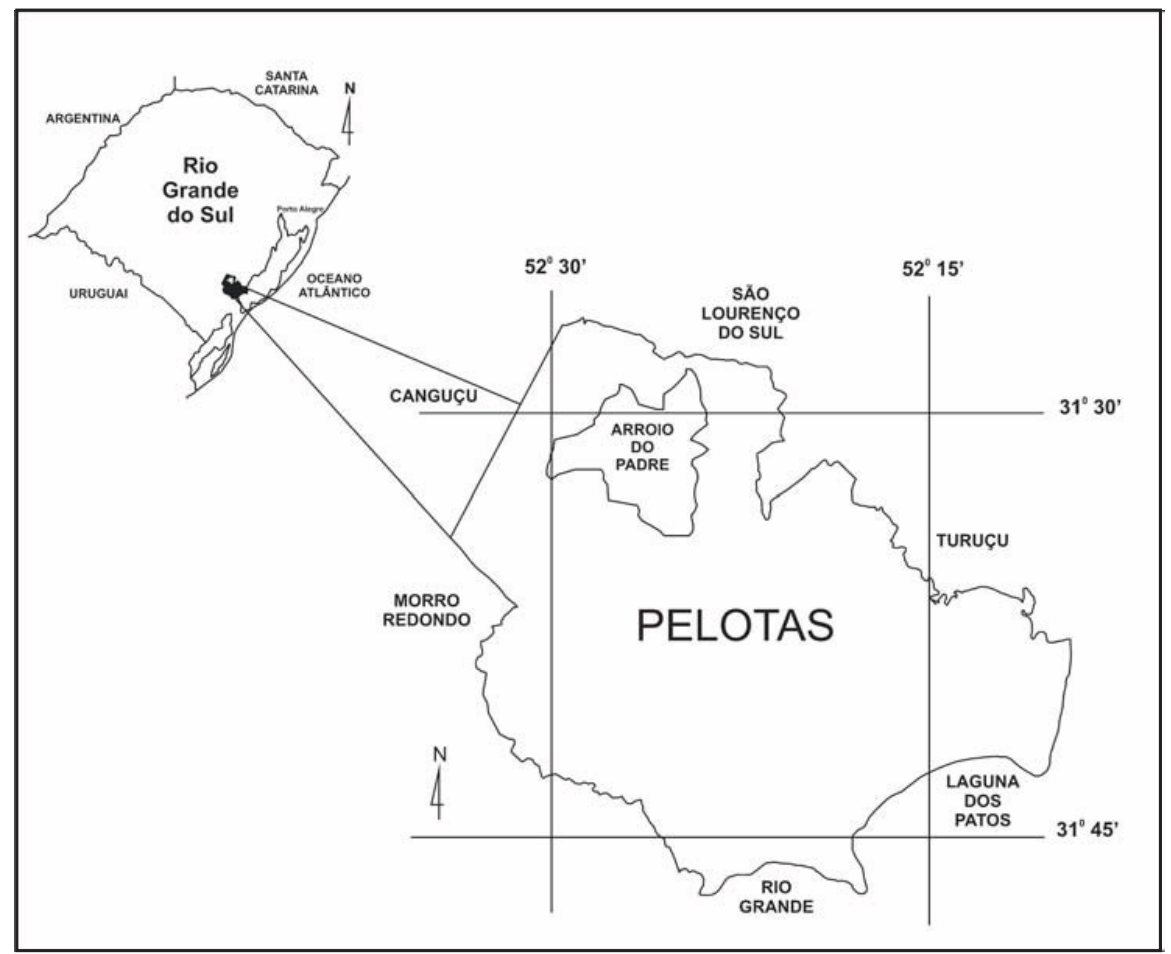

Mapa 1 - Localização do município de Pelotas/RS.

Fonte: SIMON, A. L. H., 2007.

\section{A AGROECOLOGIA NO MUNICÍPIO DE PELOTAS}

No município de Pelotas foi a partir de 1984 que se iniciaram as atividades relacionadas à agroecologia. A Pastoral Rural (ligada à Diocese da Igreja Católica) começou um trabalho de incentivo à agroecologia junto aos produtores familiares do município, por meio de cursos de formação, visitas a Centros de Agricultura Ecológica e implementação de experiências locais, com trabalhos de referência em unidades familiares do município. No ano de 1995, a Pastoral Rural priorizou o trabalho de assessoria na organização dos agricultores que adotaram o sistema agroecológico, a fim de que estes pudessem comercializar adequadamente seus produtos.

Prestando assessoria aos grupos de pequenos agricultores no município, a Pastoral Rural busca disponibilizar técnicas alternativas sustentáveis de manejo de culturas integrando os princípios de preservação ambiental com rendimentos satisfatórios na produção dos alimentos cultivados, buscando ainda, garantir a comercialização dos produtos visando que o produtor rural obtenha renda em detrimento da diferenciação de sua produção.

A Pastoral firmou também convênio com o Centro de Apoio ao Pequeno Agricultor - CAPA (São Lourenço do Sul), com o objetivo de oferecer assistência técnica, na área da agroecologia, aos produtores familiares de Pelotas. Como resultado desta ação conjunta, em 1995, foi fundada a Associação Regional de Produtores Agroecológicos da Região Sul - ARPASUL e, em novembro do mesmo ano, foi inaugurada a primeira feira de produtos 
agroecológicos da região sul do estado, na cidade de Pelotas.

Atualmente, a produção de base agroecológica, dos produtores cadastrados que recebem assessoria da ARPASUL da região de Pelotas, é destinada para a feira ecológica realizada semanalmente na cidade e parte para os programas de bolsa alimentação do governo federal. Estão cadastradas na ARPASUL, recebendo assistência técnica na produção e comercialização, em torno de 56 famílias de produtores rurais, distribuídas nos municípios de Canguçu, Pelotas, Morro Redondo e Capão do Leão.

Destaca-se a importância do Centro de Apoio ao Pequeno Agricultor - CAPA como responsável pela sistematização da produção e extensão rural, o referido centro foi fundado em 1978 pela Igreja Evangélica de Confissão Luterana no Brasil - IECLB, e suas atividades começaram em 1979 com a implantação do escritório no município de Santa Rosa/ RS, núcleo este, que em 1988 foi transferido para Erechim/RS. No município de Pelotas, o CAPA surgiu depois da transferência do escritório de São Lourenço para o município, no ano de 2001 (BUCHWEITZ; MENEZES, 2003).

O CAPA trabalha diretamente com os agricultores familiares abrangendo desde aspectos técnicos voltados para a extensão e auxílio na produção orgânica como aspectos sociais, engajando os agricultores e fomentando sua formação política. Os princípios do CAPA estão diretamente vinculados aos ideais da sustentabilidade, percebendo o potencial altamente favorável da agricultura familiar para a conversão dos agroecossistemas convencionais em agroecossistemas de base agroecológico. O Centro sistematiza suas ações no desenvolvimento de estratégias que consolidem uma estrutura de produção e comercialização dos produtos orgânicos por meio de metodologias participativas onde os agricultores participam ativamente do processo decisório. Mesmo tendo sido criado pela IECLB o CAPA "trabalha com agricultores familiares de todos os credos e raças, sem distinção político-ideológica" (BUCHWEITZ ; MENEZES, 2003, p. 192).
Outra importante cooperativa que trabalha com a produção de base agroecológica no município é a Sul - Ecológica. Uma cooperativa fundada em dezembro de 2001, surgindo a partir de associações e cooperativas de agricultores familiares da região sul do Rio Grande do Sul, como necessidade frente ao modelo de modernização da agricultura que se intensificava no meio rural.

No total, a cooperativa possui 250 associados, sendo 67 pertencentes ao município de Pelotas, e os demais se distribuem pelos municípios de Canguçu, Herval, São Lourenço do Sul, Turuçu, Capão do Leão, Arroio do Padre e Morro Redondo. A cooperativa também possui um significativo número de associados constituídos de assentados da reforma agrária e remanescentes de quilombolas. A Sul - Ecológica busca fomentar a produção ecológica incentivando sua produção e sistematizando a comercialização da mesma, ainda, agregar valor aos produtos da agricultura familiar melhorando a qualidade de vida no meio rural, formando e capacitando seus associados para a agroecologia.

O número total de associados da cooperativa Sul-Ecológica no município de Pelotas é de 67 agricultores, entretanto, em uma mesma família é encontrado mais de um sócio, o que reduz o número de famílias que trabalham com a produção de base agroecológica deste total de 67 associados.

\section{METODOLOGIA DA PESQUISA}

Para a efetivação do projeto foi realizada uma revisão teórica sobre o segmento da produção agrícola familiar e sobre os princípios teórico-metodológicos da agroecologia, a fim de fornecer subsídios para a interpretação e confrontação das teorias existentes com a realidade empírica encontrada, no caso, a realidade dos produtores familiares de base agroecológica do município de Pelotas/RS.

Para um diagnóstico da atual situação em que se encontram os produtores do município e a produção de base agroecológica foram utilizados dados fornecidos por fontes secundárias como a cooperativa 
Sul - Ecológica, além do Centro de Apoio ao Pequeno Agricultor - CAPA do município de Pelotas. É importante justificar a escolha da cooperativa Sul Ecológica como consulta para base cadastral, pois isso se deve ao fato que esta cooperativa é a que possui o maior número de associados que trabalham com a produção orgânica do município e também seu cadastro de produtores apresenta-se bastante completo, com informações como localização/ endereço das unidades produtivas.

Para conhecimento da realidade empírica foram realizadas entrevistas baseadas em roteiros semi-estruturados que possibilitassem abranger a totalidade das variáveis a serem analisadas no projeto (indicadores sociais, técnicos e de produção). As entrevistas foram realizadas com 11 agricultores e como se trata de um estudo de caso, não foi utilizado nenhum método estatístico de caráter quantitativo para definição da amostra, mas, um método amostral qualitativo, que possa dar conta da abrangência de variáveis previamente definidas a serem investigadas.

\section{PERFIL DA PRODUÇÃO DE BASE Agroecológica do MUNiCíPIO DE PELOTAS/RS}

No caso analisado no município de Pelotas, encontramos um total de 27 pessoas das famílias que trabalham diretamente na produção de base agroecológica, desenvolvendo todas as atividades necessárias, desde a produção até a colheita dos produtos, esta quantidade é bastante baixa visto que encontramos uma média de menos de 03 pessoas por família, em cada unidade produtiva.

Entretanto, em apenas 02 unidades foi citada a utilização de mão-de-obra externa, esta força de trabalho é apenas empregada temporariamente, quando as atividades agrícolas apresentam-se mais intensas. Esta característica é central deste tipo de organização, o uso da mão-de-obra familiar é um traço fundamental na organização familiar de produção.

A faixa etária do grupo familiar é bastante diversificada, mas, apenas em uma família foi encontrada uma pessoa acima de 60 anos de idade, o grupo mais representativo foi encontrado entre a faixa etária de 50 a 60 anos, representando 10 pessoas do total de que compõem os grupos familiares. Pode-se perceber assim, que no caso analisado há um processo de envelhecimento do campo, pois, mesmo se apresentando significativamente o grupo compreendido entre os 11 e 30 anos, as pessoas desta faixa etária, geralmente, são os filhos de agricultores que, posteriormente, tendem a abandonar a unidade produtiva, principalmente no caso das filhas, que se direcionam para a cidade na busca de empregos e/ou para continuarem seus estudos.

A escolaridade das pessoas que compõem o grupo familiar é considerada baixa, entre os proprietários, apenas 01 possui o ensino superior completo, a mesma quantidade é encontrada para o ensino médio incompleto, enquanto que 02 proprietários possuem o ensino médio completo, e 07 proprietários possuem apenas o ensino fundamental incompleto, caracterizado muitas vezes somente pela conclusão das séries iniciais. Todas as crianças e adolescentes que compõem o grupo familiar dos produtores de base agroecológica em idade escolar freqüentam a escola regularmente.

Em relação à área física das unidades familiares, de acordo com a tabela 1, percebe-se que as mesmas não possuem uma área física representativa, 07 unidades apresentam área entre 01 e 10 hectares, sendo que deste total, 05 unidades possuem área inferior a 05 hectares, ainda, não foi encontrada nenhuma unidade de produção que ultrapassasse os 40 hectares. Esta característica no caso específico da produção de base agroecológica reveste-se de importância, pois facilita a transição total do agroecossistema de uma agricultura convencional para o de base agroecológica.

Ao analisar as possibilidades de desenvolvimento da agroecologia relacionada à sua escala de ocorrência, Gliessman afirma:

Os princípios agroecológicos são melhor aplicados em uma escala relativamente pequena. Isso 
Agricultura familiar e agroecologia: perfil da produção de base agroecológica do município de Pelotas/RS Roberto Antônio Finatto, Giancarla Salamoni

encoraja a produção para o consumo regional, em vez da exportação. São também mais compatíveis com formas mais equitativas de propriedade da terra e de repartição dos benefícios econômicos, do que com a concentração de terras agrícolas nas mãos de poucos. (GLIESSMAN, 2005, p. 609).

Tabela 1 - Área física das unidades familiares de base agroecológica no município de Pelotas/RS.

\begin{tabular}{cc}
\hline Área Física das Unidades (ha) & $\mathrm{N}^{\mathrm{o}}$ de Unidades Produtivas \\
\hline $01-10$ & 07 \\
\hline $11-20$ & 02 \\
\hline $21-30$ & 01 \\
\hline $31-40$ & 01 \\
\hline
\end{tabular}

Fonte: Trabalho de campo, 2007.

No que concerne ao número de anos trabalhados com as atividades de base agroecológica todos os produtores entrevistados trabalham há 03 anos ou mais com estas atividades ( 01 agricultor desenvolve atividades há 03 anos; 04 produtores trabalham há 04 anos; 05 produtores trabalham há 03 anos; 01 produtor trabalha com a produção de base agroecológica há 06 anos e 02 já fazem há mais de dez anos).

Quanto aos produtos cultivados pelos agricultores, apenas uma agricultora cultiva frutas com objetivo comercial, como amoras e goiabas, que são transformadas em suco e, posteriormente, comercializado na sede da cooperativa Sul-Ecológica. Os demais agricultores entrevistados desenvolvem atividades produtivas ligadas à olericultura (cenoura, beterraba, repolho, couve-flor, etc.). Assim, 09 produtores cultivam tanto olericulturas quanto frutas (comercializadas eventualmente, quando disponíveis na unidade produtiva) e apenas 2 produtores cultivam somente olericulturas.

A criação de animais é considerada como atividade secundária, e os produtos dela obtidos são consumidos diretamente na unidade produtiva, sendo eventualmente destinados ao consumidor externo. $\mathrm{O}$ único produto que adquire importância para a comercialização é o leite, que em alguns casos é uma das principais fontes de renda para os agricultores.

A produção de base agroecológica adquire importância econômica para as famílias do município de Pelotas, quando os agricultores foram perguntados sobre qual(is) recurso(s) representava ou representavam as principais fontes de receita da unidade produtiva, as olericulturas foram citadas 07 vezes, a fruticultura 05 vezes, seguida pela aposentadoria e pelo leite que representam 04 respostas cada um.

Nota-se que os agricultores possuem mais de um produto entre os principais responsáveis pela renda da família. Neste sentido, pode-se inserir a produção de base agroecológica no contexto das estratégias econômicas de reprodução da agricultura familiar como alternativa de renda para os agricultores do município. A renda gerada pela comercialização dos produtos é fundamental no contexto das unidades produtivas familiares.

Ainda pode-se perceber o desenvolvimento da produção de base agroecológica no município de Pelotas, 06 agricultores entrevistados trabalham apenas com a produção de base agroecológica, em contrapartida, 05 trabalham com produção de base agroecológica e com algum outro produto em sistema convencional. Esta ainda é uma barreira a ser superada, pois alguns produtores ainda se dividem entre a produção de base agroecológica e a convencional que exige altos índices de agrotóxicos, como a produção de fumo.

A produção de base agroecológica é destinada, de acordo com a tabela 2, em sua maioria, para o 
Programa de Aquisição de Alimentos - PAA, sendo que 10 produtores destinam sua produção para este programa. O Programa de Aquisição de Alimentos é uma ação do governo federal que, "busca garantir o acesso aos alimentos em quantidade, qualidade e regularidade necessárias às populações em situação de insegurança alimentar e nutricional e promover a inclusão social no campo por meio do fortalecimento da agricultura familiar." (Ministério do Desenvolvimento Social e Combate à Fome, 2007).

As feiras livres representam um importante destino para a produção de base agroecológica, sendo que 04 produtores comercializam em feiras que são realizadas semanalmente no centro da cidade de Pelotas. Já o comércio atacadista representa, para 03 produtores, um meio de escoamento da produção e no posto de comercialização, localizado na sede da Cooperativa Sul - Ecológica, são comercializados, no varejo, os produtos de base agroecológica do município.

Ao analisar o perfil do feirante ecológico do município de Pelotas, Sacco dos Anjos, Godoy e Caldas (2005) escrevem que,

[...] os feirantes ecológicos trabalham com base em princípios associativos. Sob uma mesma lona, vendem seus produtos e respondem pela gestão do espaço de comercialização, assim como por etapas que envolvem a logística de funcionamento do ponto de vista da coleta dos produtos junto às propriedades rurais. (SACCO DOS ANJOS; GODOY; CALDAS, 2005, p. 145).

Este princípio de cooperação é perceptível entre os agricultores do município, estes se ajudam mutuamente desde o processo de recolhimento da produção no interior do município até no momento da comercialização na cidade. Esta cooperação inserese no contexto das estratégias para os agricultores, na medida em que organizados em grupos, ele podem diversificar a oferta de produtos oferecidos.

É importante destacar que os agricultores possuem mais de um local para comercialização e dependendo do ritmo de sua produção podem possuir dois ou três locais de comercialização, a fim de conseguir mercado consumidor que possa absorver a quantidade de produtos disponíveis.

Apenas uma família entrevistada destina sua produção por meio de entrega diretamente com o comércio varejista, principalmente em fruteiras, realizada 2 ou 3 vezes durante a semana. Esta mesma família é a que apresenta o maior grupo familiar entre os agricultores entrevistados, ou seja, como possui mão-de-obra suficiente tende a produzir mais e a encontrar outros meios para comercializar seus produtos.

Tabela 2 - Destino da produção de base agroecológica dos agricultores do município de Pelotas/RS.

\begin{tabular}{cc}
\hline Destino da produção & $\mathrm{N}^{\circ}$ de Unidades Produtivas \\
\hline Comércio atacado & 02 \\
\hline Feira Livre & 04 \\
\hline Ponto de venda na Cooperativa & 03 \\
\hline Programa de Aquisição de Alimentos/PAA & 10 \\
\hline
\end{tabular}

Fonte: Trabalho de campo, 2007.

Sobre a rede de comercialização organizada pela cooperativa, os agricultores a consideram bastante importante, pois, de acordo com um agricultor, "tu tira o atravessador que é um dos problemas que o pequeno agricultor tem (Agricultor
A, pesquisa de campo, 2007). Outra produtora comenta: "A melhor forma que foi implantada é essa pela cooperativa que junto com o próprio agricultor resolve e não tem intermediário, ele produz e comercializa" (Agricultora B, pesquisa de campo, 
2007), referindo-se à feira ecológica organizada pela cooperativa.

Para o trabalho nas lavouras, de acordo com a tabela 3, as atividades são basicamente manuais, os agricultores não possuem maquinário agrícola em número representativo. Apenas 03 produtores possuem trator, 09 possuem pulverizador, 09 possuem arado, 10 possuem grade e apenas 04 possuem motoserra. Os equipamentos, como o arado e a grade, são movidos à tração animal. Como apenas 03 produtores possuem trator, os demais preferem pagar por hora de serviço utilizada com o trator de um vizinho, pois seu uso ocorre de maneira limitada, e, assim, não há custos com manutenção do equipamento.

Tabela 3 - Tipo e número total de equipamentos agrícolas utilizados na produção de base agroecológica no município de Pelotas/RS.

\begin{tabular}{cc}
\hline Tipo de equipamento & $\mathrm{N}^{\mathbf{0}}$ total de equipamentos encontrados \\
\hline Trator & 03 \\
\hline Pulverizador & 09 \\
\hline Arado & 09 \\
\hline Grade & 10 \\
\hline Motoserra & 04 \\
\hline
\end{tabular}

Fonte: trabalho de campo, 2007.

Para o cultivo dos produtos, todos os produtores entrevistados (11 agricultores) recebem assistência técnica dos agrônomos e técnicos agrícolas do Centro de Apoio ao Pequeno Agricultor/CAPA que trabalha juntamente com a Sul-Ecológica na promoção da produção de base agroecológica, 03 produtores também recebem assistência técnica de órgãos públicos como a Empresa de Assistência Técnica e Extensão Rural - EMATER e da Empresa Brasileira de Pesquisa Agropecuária - EMBRAPA.

O uso da assistência técnica ocorre 01 vez a cada dois meses por 05 agricultores, 01 vez por mês por 04 agricultores, $01 \mathrm{vez}$ a cada três meses por 01 agricultor, e apenas 01 agricultor respondeu que utiliza a assistência técnica 01 vez ao ano. Em muitos casos, a assistência técnica não possui regularidade, os técnicos são chamados de acordo com as necessidades dos agricultores.

É importante destacar, também, que além da assistência técnica na unidade produtiva, a Cooperativa Sul - Ecológica realiza palestras e reuniões na sede das comunidades ou na casa de algum produtor onde os demais se reúnem para discutir meios de comercialização e outros aspectos relacionados à produção de base agroecológica.

Os agricultores consideram importante a cooperativa, não apenas pelas possibilidades de assessoria, mas pela cooperação coletiva que ela proporciona na busca por ideais comuns aos agricultores, de acordo com um agricultor o grupo é importante pois, por meio dele,

Os agricultores conseguem melhores incentivos, eles podem sentir que eles também têm força, tem poder estando organizados, e uma coisa é um sozinho pedindo e outra coisa é onde várias pessoas que reivindicam, cobram, então é um peso maior quando tu tem um número maior de pessoas. (Agricultor C, pesquisa de campo, 2007).

Neste sentido quando perguntados em quantos cursos, palestras ou atividades técnicas os agricultores participaram no último ano, 8 agricultores responderam que participaram de duas a cinco destas atividades e 3 responderam que participaram em mais de 5 cursos, palestras ou atualizações técnicas. 
Os agricultores também utilizam financiamento para sua produção, 07 produtores utilizam o Programa Nacional de Fortalecimento da Agricultura Familiar/PRONAF, de origem federal, 01 produtor utiliza financiamento de origem estadual, 01 produtor utiliza financiamento da Cooperativa de Crédito Rural com Interação Solidária (destinado para construção de benfeitorias) e 04 produtores não utilizam financiamento para produzir.

O que merece destaque é que nenhum produtor utiliza o PRONAF Agroecologia, que é uma linha de crédito destinado especificamente para a produção de base agroecológica ou, para a conversão de produção convencional em agroecológica. De acordo com informações disponíveis no site do Banco Nacional de Desenvolvimento Econômico e Social (2007), o PRONAF agroecologia, é considerado um "apoio financeiro para agricultores familiares enquadrados nos Grupos "C", "D" ou "E", destinado ao investimento em sistemas de produção agroecológica, incluindo-se os custos relativos à implantação e manutenção do empreendimento" (Banco Nacional de Desenvolvimento Econômico e Social, 2007).

A diferenciação de grupos do PRONAF ocorre devido a diversidade da renda do agricultor. Assim, O PRONAF Grupo C beneficia os agricultores familiares com renda familiar anual bruta superior a $\mathrm{R} \$ 4$ mil e inferior a $\mathrm{R} \$ 18$ mil; o Grupo D é específico para agricultores que possuem uma renda familiar anual bruta superior a $\mathrm{R} \$ 16$ mil e até $\mathrm{R} \$ 45 \mathrm{mil}$; o Grupo E abrange os agricultores com renda familiar bruta entre R $\$ 50$ mil até o limite de R $\$ 110$ mil.

Riechel considera que,

O Programa foi lançado oficialmente pelo governo brasileiro em 1995, como uma linha especial de crédito de custeio, denominada de Plano Nacional da Agricultura Familiar (PLANAF). Sua institucionalização e regulamentação como programa governamental ocorreu em junho de 1996, quando passou a integrar o Orçamento Geral da União. Em 1999, passa a ter a denominação atual. (RIECHEL, 2006, p. 08 e 09).
Ainda, sobre o PRONAF, Sacco dos Anjos escreve que "foi concebido como programa destinado a potencializar o desenvolvimento rural, tendo na agricultura familiar o referente e eixo central de sustentação, orientando-se fundamentalmente rumo à geração de emprego e renda no meio rural." (SACCO DOS ANJOS, 2003, p. 272)

Acerca das dificuldades relacionadas à agricultura e à produção de base agroecológica, os agricultores, apesar de considerarem que sua vida tem melhorado nos últimos anos e que a associação representou um significativo avanço na organização da cadeia produtiva dos produtos, reconhecem que ainda existem dificuldades que, se superadas, promoveriam o desenvolvimento da produção.

As dificuldades relacionadas ao acesso ao crédito, insumos e quanto ao local de comercialização da produção foram as mais citadas, posteriormente, aparecem as dificuldades relacionadas à falta de mãode-obra para trabalhar nas atividades agrícolas e as relacionadas às pesquisas, principalmente as de mercado para diagnóstico das demandas do mesmo, o que possivelmente favorecerá uma melhor comercialização dos produtos. A dificuldade relacionada à assistência técnica foi citada apenas uma vez, o que representa um fator positivo, visto que os agricultores estão amparados pela Cooperativa SulEcológica e pelo Centro de Apoio ao Pequeno Agricultor.

\section{CONSIDERAÇÕES FINAIS}

No caso específico do município de Pelotas RS, constatou-se que a produção de base agroecológica está se expandindo ao longo do tempo, tanto no aspecto quantitativo, em relação ao número de produtores trabalhando nesta atividade, quanto na diversidade dos produtos cultivados disponíveis para comercialização.

Para tanto, destaca-se a importância da Cooperativa Sul-Ecológica e do Centro de Apoio ao Pequeno Agricultor - CAPA, entre outras Organizações Não-Governamentais e cooperativas, 
para a sistematização da produção e comercialização dos produtos. Surgida devido à necessidade de uma organização dos produtores a Sul - Ecológica iniciou seus trabalhos voltados diretamente para o estímulo da produção agroecológica no município.

As unidades produtivas apresentam, em sua maioria, menor dimensão territorial o que representa a possibilidade de uma conversão total em seus sistemas agrícolas, de convencionais para agroecológicos. Isto se justifica pelo próprio interesse dos agricultores, visto que, todos eles responderam que têm interesse em ampliar sua produção se houvesse um suporte técnico e um sistema de comercialização que absorvesse os produtos cultivados.

Quanto à diversidade da produção, apesar do relativo aumento, percebe-se que ainda está restrita aos hortigranjeiros, pois estes produtos necessitam de menor emprego de mão-de-obra durante o cultivo. A disponibilidade de mão-de-obra é reflexo da situação do grupo familiar que, em sua maioria, não apresenta um número significativo de componentes para realizar as atividades agrícolas e, os filhos dividem seu tempo entre o trabalho na unidade produtiva e a escola. Ainda, em alguns casos, os filhos mais velhos deixaram a propriedade, seja para estudar ou trabalhar, não podendo ser contabilizados como força de trabalho disponível.

Percebeu-se que a dificuldade de comercialização ainda é um problema encontrado pelos agricultores, ainda que a cooperativa desempenhe a função de mediar as relações entre produtores e consumidores, se faz necessário ampliar tanto o volume da produção, quanto a sua diversidade, garantindo um mercado estável que atenda as necessidades de escoamento da produção.

No que se refere à relação entre a agricultura de base agroecológica, praticada no município e, os pilares da sustentabilidade, algumas lacunas ficam evidentes. Amparada nos pilares da sustentabilidade a agroecologia propõe uma maior amplitude dos benefícios gerados pela agricultura e os setores que a ela se vinculam, como mercado consumidor, origem dos insumos, disponibilidade e acesso a crédito rural, entre outros. Porém, no caso analisado, percebe-se que os sistemas produtivos estão muito mais próximos de uma agricultura orgânica (de caráter mais técnico) do que propriamente da agroecologia que expande os benefícios da agricultura para além do campo e da organização da produção.

Ainda, para a concretização da organização de um sistema agroecológico, portador de transformações econômicas, políticas e socioambientais, a agricultura como um todo deve tornar-se verdadeiramente sustentável e, os aspectos da produção, distribuição e consumo de alimentos precisam estar compatíveis com os pressupostos da agroecologia.

Conclui-se afirmando que, no município de Pelotas, a agroecologia apresenta possibilidades de desenvolvimento, desde que sejam efetuadas ações conjuntas entre agricultores, cooperativas/associações e a comunidade em geral. Cabe, de imediato, ao poder público garantir maiores incentivos a estes agricultores e democratizar as linhas de crédito para que facilite o acesso dos agricultores às mesmas, criando condições para que os princípios da produção agroecológica possam ser adotados pelo segmento da agricultura familiar.

\section{REFERÊNCIAS}

ABRAMOVAY, Ricardo. Paradigmas do Capitalismo Agrário em Questão. São Paulo: Hucitec/ANPOCS/UNICAMP, 1992. 275p.

ALTIERI, Miguel M. Agroecologia: a dinâmica produtiva da agricultura sustentável. Porto Alegre: Ed. Universidade/UFRGS, 1998.95 p.

Banco Nacional de Desenvolvimento Econômico e Social. Disponível em < www.bndes.gov.br/programas/ agropecuarios/pronaf.asp $>$ Acesso em 08 dez. 2007.

BECKER, Dinizar Fermiano (Org.). Desenvolvimento Sustentável: Necessidade e/ou 
Agricultura familiar e agroecologia: perfil da produção de base agroecológica do município de Pelotas/RS

Roberto Antônio Finatto, Giancarla Salamoni

Possibilidade?. Santa Cruz do Sul: EDUNISC, 2002. $134 \mathrm{p}$.

BEZERRA, Maria do Carmo Lima; VEIGA, José Eli da (Orgs.) Agricultura sustentável: subsídios à elaboração da agenda 21 brasileira. Brasília: Ministério do Meio Ambiente; Instituto Brasileiro do Meio Ambiente e dos Recursos Naturais Renováveis; Consórcio Museu Emílio Goeldi, 2000. 190p.

BRUMER, Anita. Transformações e estratégias produtivas na produção familiar na agricultura gaúcha. Cadernos de Sociologia. Porto Alegre, v.6, n.1,p. 98-11, 1994.

BUCHWEITZ, Suzanne; MENEZES, Paulino. O tempo compartilhado: 25 anos do CAPA. Porto Alegre/RS, Centro de Apoio ao Pequeno Agricultor, 2003. 200p.

CANUTO, J. C.; SILVEIRA, M. A. da; MARQUES, J. F. O sentido da agricultura familiar para o futuro da agroecologia. Ciência \& Ambiente, Santa Maria, v. 1, n.1, p. 57-63, 1994.

CANUTO, João Carlos. A pesquisa e os desafios da transição agroecológica. Ciência \& Ambiente, Santa Maria, v. 1, n. 27, p. 133-140, 2003.

CANDIOTTO, Luciano Z. P.; CORRÊA, Walquíria Kruger. Desenvolvimento rural sustentável: algumas considerações sobre o discurso oficial do governo federal. Geografia, Rio Claro, v. 29, n. 2, p. 265280, 2004.

CAPORAL, Francisco Roberto; COSTABEBER, José Antônio. Análise Multidimensional da Sustentabilidade: Uma proposta metodológica a partir da Agroecologia. Revista Agroecologia e Desenvolvimento Rural Sustentável, Porto Alegre, v.3, n.3, p. 70-85, 2003.

CAPORAL, Francisco Roberto; COSTABEBER, José Antônio. Agroecologia: Alguns conceitos e princípios. Brasília: MDA/SAF/DATER-IICA, 2004. $24 \mathrm{p}$.
CHAYANOV, Alexander V. La Organización de la Unidad Económica Campesina. Buenos Aires: Ediciones Nueva Visión, 1974. 338p.

GLIESSMAN, Stephen R. Agroecologia: processos ecológicos em agricultura sustentável. Porto Alegre: Editora da UFRGS, 2005. 653 p.

KAUTSKY, Karl. A Questão Agrária. São Paulo: Proposta Editorial, 1980. 329 p.

LAMARCHE, Huges. Agricultura familiar: Comparação Internacional. Campinas/SP: Ed: UNICAMP, 1993. 336p.

LAMARCHE, Huges. Agricultura familiar: do mito à realidade. Campinas-SP: Ed. UNICAMP, 1998. 348 p.

Ministério do Desenvolvimento Social e Combate à Fome. Disponível em: <http://www.mds.gov.br $>$. Acesso em 10 ago. 2007.

MONTIBEller $\mathrm{F}^{\circ}$, Gilberto. O Mito do Desenvolvimento Sustentável: meio ambiente e custos sociais no moderno sistema produtor de mercadorias. Florianópolis: Ed. Da UFSC, 2004. 306p.

Núcleo de Estudos Agrários e Desenvolvimento Rural - NEAD. Disponível em www.nead.org.br/ Acesso em 08 dez. 2007.

OLIVEIRA, Ariovaldo Umbelino de. A Agricultura Camponesa no Brasil. São Paulo: Contexto, $1991.164 \mathrm{p}$.

PASTORAL RURAL DA DIOCESE DE PELOTAS. Agricultura Ecológica - insumos alternativos. Pelotas, 1998. (Cadernos Subsídio n.1).

Agroecologia - Proposta de assessoria da Pastoral Rural. Pelotas, 1998. (Cadernos Subsídio nº 2).

RIECHEL Damaris. Crédito rural, extensão rural e agroecologia: Uma experiência com produtores de 
Agricultura familiar e agroecologia: perfil da produção de base agroecológica do município de Pelotas/RS Roberto Antônio Finatto, Giancarla Salamoni

base agroecológica no Distrito de Cerrito Alegre Pelotas/RS. (Artigo do curso de Especialização em Geografia). Universidade Federal de Pelotas. 2006.

ROSA, Mário. Geografia de Pelotas. Pelotas: UFPel, $1985.333 \mathrm{p}$.

SACHS, Ignacy. Estratégias de transição para o século XXI: desenvolvimento e meio ambiente. São Paulo: Studio Nobel, 1993. 103 p.

SACCO DOS ANJOS, Flávio. Agricultura Familiar, Pluriatividade e Desenvolvimento Rural no Sul do Brasil. Pelotas/RS: EGUFPEL, 2003. 374p.

SACCO DOS ANJOS, Flávio; GODOY, Wilson Itamar; CALDAS, Nádia Velleda. As feiras-livres de Pelotas sob o império da globalização: perspectivas e tendências. Pelotas/RS: Editora e Gráfica Universitária, 2005. 195 p.

SALAMONI, Giancarla. Produção familiar: possibilidades e restrições para o desenvolvimento sustentável - o exemplo de Santa Silvana - Pelotas RS. 2000. 331f. Tese. (Doutorado em Geografia.). Universidade Estadual Paulista Júlio de Mesquita Filho, Rio Claro - SP, 2000.

SANTOS, Milton. A Natureza do Espaço: espaço e tempo, razão e emoção. São Paulo: HUCITEC, 1997. $308 \mathrm{p}$.

SILVA, Osvaldo Heller da. Alguns comentários sobre o destino do campesinato em Marx. Revista Economia Rural, Brasília, v.24, n.1, p. 101-116, 1986.

SIMON, A. L. H. A Dinâmica do Uso da Terra e sua Interferência na Morfohidrografia da Bacia do Arroio Santa Bárbara - Pelotas (RS). 2007.185f. Dissertação (Mestrado em. Geografia) Universidade Estadual Paulista Júlio de Mesquita Filho, Rio ClaroSP, 2007.

WANDERLEY, Maria de Nazareth Baudel. Em Busca da Modernidade Social. Uma Homenagem a Alexander V. Chayanov. Campinas: UNICAMP, 1989. 33p. 